http://jmscr.igmpublication.org/home/ ISSN (e)-2347-176x ISSN (p) 2455-0450 crossref DOI: https://dx.doi.org/10.18535/jmscr/v9i2.05

\title{
Management of parturient with acute pulmonary edema undergoing cesarean section
}

\author{
Authors \\ Dr Ankita Chandel ${ }^{1}$, Dr Nisha Sharma ${ }^{2^{*}}$, Dr Bhawna Ahluwalia ${ }^{3}$, \\ Dr Ravinder Thakur ${ }^{4}$, Dr Anmolpreet Kaur ${ }^{5}$ \\ ${ }^{1}$ Assistant Professor, Dr Radhakrishnan Government Medical College, Hamirpur \\ ${ }^{2,3,4}$ Senior Resident, Dr Radhakrishnan Government Medical College, Hamirpur \\ ${ }^{5}$ Resident, Government Medical College, Chandigarh \\ *Corresponding Author \\ Dr Nisha Sharma
}

\begin{abstract}
Pulmonary edema is a rare complication of pre-eclampsia. We report a case of severe pre-eclampsia and pulmonary edema, managed under general anesthesia for caesarean section followed by elective ventilation in intensive care unit.
\end{abstract}

\section{Introduction}

Acute pulmonary edema affects about $0.05 \%$ women during pregnancy and post partum, with pre eclampsia and eclampsia as the major cause. Hypertensive disease of pregnancy affects approximately $15 \%$ of pregnant women. Pre- eclampsia is a multisystem major cardiovascular disease of pregnancy with hypertension its main clinical manifestation., ${ }^{1,2}$ Acute pulmonary oedema, which signifies severe disease, is a leading cause of death in women with pre- eclampsia. ${ }^{3}$

It is characterised by sudden- onset breathlessness, may be accompanied by agitation, and is often the serious clinical manifestation of a variety of pathophysiological processes. Acute pulmonary oedema may be caused by a variety of perturbations of any one of the key determinates of cardiovascular function and fluid flow into the pulmonary interstitium. ${ }^{4}$

The pathogenesis of pulmonary edema complicating pre-eclampsia and eclampsia is a subject of extensive investigation. The patients with pre-eclampsia usually have generalised arterial vasospasm resulting in an increased systemic vascular resistance (increased after load), reduced plasma volume (decreased pre-load), and increased left ventricular stroke work index (hyperdynamic heart). ${ }^{5}$

Here we report a case of pregnant parturient with pre eclampsia complicated by acute pulmonary edema presented to the emergency department with respiratory failure and acidosis.

\section{Case Report}

A 28 years old primigravida presented to the emergency department at 36 weeks gestation. She 
was tachypneic. Her vitals were blood pressure $170 / 110 \mathrm{mmHg}$, heart rate 120 /minute, respiratory rate $36 / \mathrm{min}$, oxygen saturation $70 \%$ with bilateral pitting edema. She was immediately provided with high flow oxygen through venturi mask, her saturation improved to $92 \%$. She was having crepitations in the mid and lower lung region. Airway was normal. Iinvestigations available were- WBC 7000/ $/ \mathrm{mm}^{3}$; $\mathrm{Hb} 8.9 \mathrm{~g} / \mathrm{dL}$; platelets, $270 \times 109 \mathrm{~L}$; INR 1.0; urine sugar nil and albumin $3+$ on dipstick.

Patient was diagnosed to have pulmonary edema superimposed on pre eclampsia. Arterial blood gases showed metabolic acidosis with hypoxia. Patient was given intravenous (IV) furosemide 20 $\mathrm{mg}$ and iv labeatalol $20 \mathrm{mg}$. She was planned to undergo emergency caesarean section owing to fetal tachycardia.

Preoperative saturation was $89 \%$ on oxygen via mask but the patient was unable to lie down because of dyspnea so she was kept propped up with back support. The patient was attatched with multiparameter monitors (non-invasive blood pressure, cardioscopy, pulse oximetry).The saturation increased to $94 \%$ with $100 \% \mathrm{O}_{2}$. Rapid sequence induction was done with IV thiopentone sodium $3 \mathrm{mg} / \mathrm{kg}$ and IV suxamethonium 1.5 $\mathrm{mg} / \mathrm{kg}$. Pt was intubated with a 7 number cuffed endotracheal tube. Anesthesia was maintained with $\mathrm{O}_{2}+$ air + isoflurane $0.6-0.8 \%$. A central venous catheter was passed in the right internal jugular vein to guide fluid management. Following delivery of the fetus, IV oxytocin infusion was started. Patient was given IV vecuronium $5 \mathrm{mg}$, and IV fentanyl $100 \mathrm{mcg}$ for analgesia. Patient received $50 \mathrm{~mL}$ of colloid and $100 \mathrm{~mL}$ of Ringer's lactate intra operatively. The baby was born alive, APGAR 1 (1st min)/5 (10th min), and was sent to the neonatal intensive care unit (NICU).

At the end of surgery, patient was shifted to the ICU intubated and put on a ventilator on pressure control mode, curarised with IV vecuronium. Chest radiograph showed bilateral pulmonary infiltrates. ABG revealed metabolic acidosis.
Blood pressure was $176 / 110 \mathrm{~mm} \mathrm{Hg}$. Injection morphine $9 \mathrm{mg}$ supplemented, frusemide $20 \mathrm{mg}$ repeated. Patient also was started on IV labetalol infusion @ $10 \mathrm{mg} / \mathrm{h}$. Serial ABGs showed improvement in the acid-base status. Over the course of 2 days patient's vitals stabilized and gradually weaned; extubated on the fourth postoperative day and transferred to the general ward.

\section{Discussion}

Pulmonary edema complicates about $0.05 \%$ of pregnancies, ${ }^{5}$ and is a major cause of maternal as well as fetal morbidity and mortality. Many of these parturients present for emergency caesarean section posing an immense challenge to the attending obstetrician and anaesthetist as well.

Pulmonary edema further poses danger if it follows pre eclampsia in a parturient. The preeclamptic parturients are already volume depleted, and have reduced serum albumin, elevated left ventricular after load, and systolic and diastolic myocardial dysfunction. ${ }^{6}$ Increased capillary permeability may also occur. Meticulous preparation and timely intervention helped us to have a successful maternal and fetal outcome.

Our patient presented with acute dyspnea secondary to pulmonary edema, and treatment included oxygen, diuretics, fluid restriction to achieve reduction of preload and after load. Because maternal oxygen reserve are decreased in pregnancy and pulmonary edema further caused rapid desideration in our case which was managed with high flow oxygen followed by intubation in propped up position and positive pressure ventilation. Mechanical ventilaton was continued in the postoperative period to allow the lung condition to settle, to improve alveolar ventilation and re-expand the flooded alveoli.

A multi modal treatment regimen ensuring optimal oxygenation and ventilation with guarded fluid replacement remains the key to successful management. A complete understanding of the pathogenesis and symptomatic management along 
with meticulous monitoring should be the approach to ensure maternal and fetal well being.

\section{References}

1. Mushambi MC, Halligan AW, Williamson K. Recent developments in the pathophysiology and management of preeclampsia. Br J Anesth. 1996;75:133-48.

2. Benedetti, T. J., Kates, R. and Milliams, $\mathrm{V}$.: Hemodynamic observations in severe pre-eclampsia complicated by pulmonary edema. Amer. J. Obstet. \&Gynaecol., 152: 330-334, 1985.

3. Phelan, J. P. and Yurth, D. A.: Severe preeclampsia 1. Peripartum hemodynamic observations. Amer. J. Obstet. \& Gynaecol., 144: 17-22, 1982.

4. Amorim MM, Katz L, Valença M, et al. Severe maternal morbidity in an obstetric ICU in Recife, Northeast of Brasil. [Morbidadematerna grave em UTI obstétrica no Recife, regiãonordeste do Brasil]. Rev Assoc Med Bras 2008;54:261-6.

5. Yeast JD, Halberstadt G, Meyer BA, et al. The risk of pulmonary edema and colloid osmotic pressure changes during magnesium sulfate infusion. Am J Obstet Gynecol 1993;169:1566-71.

6. Thornton CE, von Dadelszen P, Makris A, et al. Acute pulmonary oedema as a complication of hypertension during pregnancy. Hypertens Pregnancy 2011;30:169-79. 